\title{
Hacia una memoria incluyente para la paz en el País Vasco
}

\author{
Xavier Mínguez Alcaide \\ Universidad del País Vasco \\ xavier.minguez@ehu.eus
}

Recibido: 22-04-2014

Aceptado: 09-02-2015

\section{Resumen}

El artículo presenta un estudio sobre la memoria colectiva en el proceso de construcción de paz en el País Vasco desde una doble perspectiva. Por un lado, la memoria colectiva como representación compartida de lo sucedido en el País Vasco durante las últimas décadas, y por otro la memoria como el derecho a la verdad de las víctimas de las vulneraciones de derechos humanos cometidas en el marco del conflicto vasco. El estudio se llevó a cabo a partir de 25 entrevistas y un espacio de diálogo, contando con la participación de personas vinculadas a partidos políticos y agentes sociales comprometidos activamente con la paz, abarcando todo el espectro sociopolítico vasco. Los resultados aportan diversas cuestiones para construir una memoria incluyente, tanto en relación a la visión del pasado, como respecto a la construcción de la verdad para reparar a las víctimas de ETA y de agentes del Estado español. Finalmente, se plantean una serie de reflexiones finales sobre el esclarecimiento de todas las vulneraciones a los derechos humanos cometidas durante el conflicto vasco, y sobre la construcción de un relato mínimo común en medio de la pluralidad de visiones sobre el pasado en la sociedad vasca.

Palabras clave: País Vasco, paz, memoria colectiva, verdad, víctimas. 


\title{
Toward an Inclusive Memory for Peace in the Basque Country
}

\begin{abstract}
The paper presents a study on collective memory in the process of peacebuilding in the Basque Country from a double perspective. On the one hand, the collective memory like shared representation of the happened in the Basque Country during the last decades, and the memory like the victims' right to the truth of the human rights violations committed in the basque conflict. The study was carried out from 25 interviews and a dialogue space, counting on the participation of tie people to political parties and social agents actively jeopardize with peace, including all basque sociopolitical field. The results provide different questions to build an inclusive memory, as much in relation to the perception of the past, like with respect to build the truth for repair the victims of ETA and agents of the Spanish state. Finally, a series of final reflections considers on clear up all human rights violations committed during the basque conflict, and on the construction of a common minimum tale in the middle of the plurality of visions on the past in the basque society.
\end{abstract}

Keywords: Basque Country; Peace; Collective Memory; Truth; Victims.

\section{Referencia normalizada}

Mínguez Alcaide, Xavier (2015): "Hacia una memoria incluyente para la paz en el País Vasco", Política y Sociedad, 52 (1), pp. 233-252.

Sumario: 1. Introducción. 2. Procedimiento del estudio. 3. Resultados del estudio. 4. Reflexiones finales. Implicaciones de una memoria inclusiva para el País Vasco. 5. Bibliografía. 


\section{Introducción}

El caso vasco es un conflicto complejo de naturaleza etnonacional, caracterizado por elementos de tipo estructural, social y psicológico, donde destacan la interdependencia negativa de las identidades colectiva vasca y española, la vulneración de Necesidades Humanas Básicas, sobre todo las de seguridad, reconocimiento e identidad, contradicciones políticas e ideológicas de naturaleza nacionalista, y factores psicosociales vinculados a la polarización social, como imágenes del enemigo en espejo, narrativas del conflicto encontradas, y lógicas de pensamiento y percepción rígidas y polarizadas (Mínguez-Alcaide, 2013). En el centro de estas cuestiones, la violencia política ha sido el anclaje principal de la realidad del País Vasco durante las últimas décadas, con la centralidad de la violencia directa ejercida por ETA, la impronta de la violencia del régimen del General Franco, la ejercida desde el Estado democrático a través del GAL, y las fuerzas y cuerpos de seguridad del Estado, o por grupos de extrema derecha como el Batallón Vasco Español.

La declaración de ETA el 20 de octubre de 2011, donde ponía punto final a la violencia ejercida durante más de 40 años, es el hito histórico que ha supuesto un punto de inflexión esencial para construir un escenario de paz sostenible en el País Vasco. En este artículo no se pretende abordar la complejidad de establecer un escenario de paz sostenible en el País Vasco, lo cual implica dimensiones de naturaleza política, social, cultural y psicosocial, sino acercarnos a un fenómeno importante para avanzar hacia la paz, la reconciliación y la reconstrucción de un tejido social fracturado por la violencia, como es afrontar el pasado, teniendo en cuenta dos dimensiones: el desarrollo de memorias colectivas más amplias y complejas, y el esclarecimiento y reconocimiento de las vulneraciones a los derechos humanos.

\subsection{Memoria colectiva y memorias en situación de conflicto profundo}

La memoria colectiva es el conjunto de significados, asunciones y creencias compartidas por los miembros de un grupo social acerca de su pasado colectivo. Podemos decir que la memoria colectiva es el conjunto de recuerdos comunes con los que un grupo describe su propio pasado (Páez, 1998). Estas representaciones del pasado son construcciones socioculturales cambiantes, que se transforman y reformulan en el marco de las prácticas sociales de los grupos, influenciadas éstas por las características coyunturales en materia política, económica y social de los diferentes momentos históricos. Así, la memoria colectiva es un fenómeno atado a los determinantes de la realidad, y las formas de interacción dentro de los grupos.

Las memorias colectivas, a la vez que representan la visión colectiva del pasado, tienen una gran importancia en la construcción subjetiva del presente. En este sentido, 
Desroche (1976) enfatiza un doble carácter de la memoria colectiva, el constitutivo y el constituyente. De manera paralela, la memoria colectiva representa una visión compartida del pasado socialmente estructurada, y participa en la construcción de la realidad subjetiva del presente y en las aspiraciones de futuro (Manero y Soto, 2005).

Por su parte, la propuesta clásica de Halbwacks (1950) indica que la memoria colectiva se construye en interacción con otros significativos en acciones comunicativas sobre el propio pasado. Estas interacciones se apoyan en marcos sociales de referencia, especialmente en ritos, ceremonias y eventos colectivos, donde se recuerdan eventos emocionalmente relevantes del pasado que, al producir fuertes identificaciones simbólicas y emotivas, sirven como referente para construir la propia identidad colectiva. Tal y como afirma Todorov (2000), en el proceso selectivo que combina recuerdo y olvido, las narrativas se construyen en base a seleccionar eventos altamente emocionales donde los grupos se otorgan un papel positivo. De este modo, vemos como los rituales de recuerdo sirven para fortalecer y consolidar la representación propia del pasado, reforzar la propia identidad colectiva, además de la lealtad al grupo y la cohesión grupal. Así, se puede observar la estrecha vinculación entre memoria e identidad colectiva, dos fenómenos centrales de los conflictos etnonacionales.

El conflicto etnonacional se produce cuando un grupo nacional o minoritario reclama el reconocimiento político y mayores cotas de soberanía al Estado (Gurr, 2000). Entre los elementos característicos de los grupos etnonacionales movilizados a favor de su soberanía política, se encuentra el desarrollo de un imaginario social sobre su ancestralidad común (Smith, 1993). Los grupos etnonacionales redescubren, redefinen y reformulan su propia cultura vernácula, reconstruyendo su memoria colectiva haciendo de ésta un elemento central en la reconstrucción de su propia identidad, y a la postre, en la movilización étnica por la soberanía política. Según este punto de vista, observamos el carácter instrumental de la memoria colectiva en este tipo de procesos, ya que, como se ha explicitado anteriormente, la memoria colectiva es un fenómeno que responde a las necesidades del presente de los grupos para fortalecer su identidad colectiva, la cohesión grupal, y una proyección colectiva hacia el futuro.

Desde un enfoque psicocultural del conflicto profundo, Ross (2010) postula que las narrativas del conflicto, como explicaciones subjetivas del mismo altamente consistentes, incluyen el rol y los motivos del propio grupo y de los otros en el estallido y escalada del mismo. Dentro de estas narrativas, parte importante de los eventos que se recuerdan están vinculados a momentos de miedo y amenaza a la propia identidad colectiva. Además, estos significados compartidos sobre nosotros, el enemigo y el conflicto tienen un carácter normativo, respondiendo a las necesidades del grupo sobre cómo sus miembros deben representar la realidad y actuar en ella.

En relación a la vinculación entre memoria e identidad colectivas, Ross (1995) afirma claramente que las memorias son visiones del pasado compartidas por los miembros de grupos que comparten una identidad. Según el autor, los significados y asunciones sobre 
el pasado estructuran el autoconcepto de los grupos, es decir, una visión compartida de quiénes son. A pesar de ello, no todos los miembros de un grupo de identidad comparten todas las asunciones sobre el pasado colectivo, existiendo variabilidad entre individuos y subgrupos en cuanto a los elementos que constituyen el recuerdo del pasado. Este fenómeno es denominado por Bourdieu (1999) como el espacio de los puntos de vista.

Esta idea nos conduce a apreciar que en el marco de un conflicto profundo, pueden coexistir diferentes visiones del pasado, más allá de las visiones fuertemente normativizadas en el seno de los grupos. A raíz del carácter estructurante de la memoria, y de la importancia de ésta para el presente, podemos encontrar disputas más o menos pronunciadas por establecer o imponer la propia visión del pasado, es decir, luchas por controlar los mecanismos de construcción y reconstrucción del pasado, y por hacer prevalecer las visiones del pasado defensivas con la propia identidad colectiva.

Desde una perspectiva netamente psicosocial, Bar-Tal (2007) indica que en situaciones de conflicto etnonacional, la memoria colectiva está vinculada a una serie de procesos psicosociales y se estructura en base a temas concretos. En cuanto a los temas, enfatiza las explicaciones y justificaciones del papel propio y ajeno en el origen y escalada del conflicto, sobre todo haciendo referencia a momentos con elevada carga emocional y simbólica. Al relatar el conflicto, los grupos realzan su autoimagen y autoestima justificando y glorificando su carácter etnocéntrico (Korostelina, 2007), enfatizan el papel de víctima del propio grupo, y producen discursos de deslegitimación del enemigo resaltando su naturaleza violenta, cruel, irracional o demoníaca, intrínseca a su identidad, y el papel de víctima del propio grupo.

El autor también señala la vinculación de la memoria colectiva con una serie de procesos de naturaleza psicosocial. En primer lugar, afirma que la memoria colectiva está vinculada a los procesos de categorización grupal, diferenciación positiva, superioridad endogrupal e identificación, propios de la teoría de la identidad social (Tajfel,1984; Turner, 1987). De igual modo, entiende que en la memoria colectiva están presentes distintos sistemas de creencias relativos a diferentes aspectos del conflicto, como es el enemigo. El desarrollo de imágenes negativas del enemigo político caracterizadas por la demonización y deshumanización, cuando se producen de manera recíproca, resultan en un proceso denominado imagen especular, uno de los principales procesos perceptivos de los conflictos etnonacionales que ayudan a explicar su difícil encauzamiento (Kelman, 1997).

Por último, advertir la presencia de procesos psicosociales de naturaleza moral que forman parte de la infraestructura psicosocial del conflicto, y que por lo tanto, están vinculados a la memoria colectiva (Coleman, 2004). Una determinada visión colectiva del conflicto puede permitir justificar la propia violencia, atribuyéndole un carácter defensivo ante la opresión o la violencia del enemigo. Así, la legitimación o justificación de la violencia aparece asociada a un proceso de desenganche moral (Bandura, 1999), según el cual las acciones violentas cometidas por el propio grupo no se interpretan 
en términos éticos o morales, y a procesos de desindividuación, deshumanización y la exclusión moral del enemigo, al cual no se aplican los criterios morales aplicables a cualquier ser humano (Haslam, 2006; Opotow, 1990).

De manera breve, hemos visto diversos elementos característicos de la memoria colectiva, haciendo énfasis en las situaciones de conflicto profundo. En situaciones de construcción de paz, como se encuentra el País Vasco en la actualidad, se otorga gran importancia a generar interpretaciones subjetivas del pasado que ayuden a un presente y un futuro en paz. Además de ello, se enfatiza una segunda dimensión de la memoria, como es el recuerdo de las víctimas de los crímenes y vulneraciones a los derechos humanos perpetradas. En este sentido, la finalidad del siguiente apartado es exponer algunos elementos sobre la construcción de la memoria de las víctimas en contextos de finalización de la violencia política, además de presentar iniciativas que se están dando en este sentido en el País Vasco.

\subsection{Iniciativas para la memoria de las víctimas en el País Vasco}

Tal y como se afirma en el estudio sobre el impacto en la salud de la violencia colectiva en el País Vasco, ISAVIC, (Larizgoitia et al., 2009), la respuesta institucional ante las víctimas de la violencia colectiva es un hecho fundamental ya que simboliza la posición de la sociedad en su conjunto ante los hechos violentos, debiendo generar cauces para enfrentar las consecuencias de la violencia, y la reconstrucción de tejidos sociales fracturados por esta. El no reconocimiento social y político de las personas que han sufrido vulneraciones a los derechos humanos es un agravante del trauma que ello supone.

La construcción de un marco para el recuerdo y la dignificación de las víctimas desde la verdad de los hechos es un elemento central para la construcción de paz. Tal y como explicita la Resolución 2005/35 de la Oficina del Alto Comisionado para los Derechos Humanos de la ONU (OHCHR, 2005), las víctimas de graves violaciones a los derechos humanos en situaciones de conflicto armado son sujetos con derecho a una reparación integral que, entre muchas cuestiones, pasa por el esclarecimiento de la verdad. Una herramienta utilizada en gran diversidad de contextos a nivel internacional es el establecimiento de comisiones de la verdad. Según Amnistía Internacional, ${ }^{1}$ entre 1974 y 2007 se crearon más 32 comisiones de la verdad alrededor del mundo, con la finalidad de esclarecer la verdad sobre los crímenes perpetrados en el marco de conflictos armados o dictaduras.

Según una publicación de la Oficina del Alto Comisionado para los Derechos Humanos de la ONU sobre cómo implementar una comisión de la verdad que sirva para impulsar un periodo transicional tras un conflicto violento, el establecimiento de un

\footnotetext{
${ }^{1}$ Ver: <http://www.amnesty.org/es/international-justice/issues/truth-commissions>.
} 
proceso de estas características requiere de un interés real de las víctimas y de la voluntad política de los agentes implicados (OHCHR, 2006). Asimismo, el informe afirma que el éxito de una comisión de la verdad pasa por la independencia operacional de sus miembros, es decir, por la posibilidad de poder trabajar sin injerencia políticas. También se indica que una comisión de la verdad debe entenderse como parte de un proceso amplio de justicia transicional y de reparación integral a las víctimas.

Por otro lado, esta publicación señala que las tareas que debe cumplir una comisión de la verdad son la toma de testimonios de personas y colectivos que han sufrido vulneraciones a los derechos humanos, generar y recopilar bases de datos sobre vulneraciones, apoyar estudios e investigaciones sobre la cuestión, posibilitar audiencias públicas donde se esclarezcan los crímenes cometidos, crear información pública a partir de informes sobre los hechos, además de aportar recomendaciones.

En la coyuntura actual del proceso vasco se está avanzando en la creación de mecanismos para una política de memoria incluyente, basada en esclarecer la verdad de las vulneraciones a los derechos humanos cometidas en el marco del conflicto vasco. A nivel estadístico y de manera general, diferentes informes señalan que ETA y grupos derivados han causado alrededor de 850 muertes y 1800 heridos, 100 personas han muerto y 650 han sido heridas por las fuerzas de seguridad del Estado español, además de 80 muertes y 320 personas heridas por parte de grupos parapoliciales como el GAL (Grupos Antiterroristas de Liberación) o grupos de extrema derecha como el Batallón Vasco-Español y la Alianza Apostólica Anticomunista (Triple A), y alrededor de 6000 pueden haber sido víctimas de torturas y malos tratos (Argituz, 2011; Martín Beristain y Páez, 2000).

Tras el anuncio de ETA del cese de su actividad armada se ha producido un avance sustancial en relación a iniciativas institucionales de paz, aunque con anterioridad ya se habían materializado diversas iniciativas jurídicas para la reparación de las víctimas y la construcción de la memoria. Con el motivo de dar luz al punto donde se encuentra esta cuestión a nivel jurídico/institucional, en este apartado haremos una breve referencia a elementos jurídicos e iniciativas institucionales vinculadas a la memoria.

A nivel jurídico/normativo, tanto desde la administración central del Estado como desde el Gobierno Vasco se han creado una serie de leyes y normas en materia de memoria histórica y de reparación a las víctimas de vulneraciones de derechos humanos que constituyen un marco jurídico de referencia al respecto. Este marco jurídico está compuesto básicamente por:

》 La Ley 52/2007, de 26 de diciembre, conocida como la Ley de Memoria Histórica, por la que se reconocen y amplían derechos y se establecen medidas a favor de quienes padecieron persecución o violencia durante la guerra civil y la dictadura.

» La Ley 4/2008, de 19 de junio, de Reconocimiento y Reparación a las Víctimas del Terrorismo. (Normativa autonómica).

» La Ley 29/2011, de 22 de septiembre de Reconocimiento y Protección Integral a las Víctimas del Terrorismo. 
» El Decreto 17/2012, de 12 de junio, de declaración y reparación de las víctimas de sufrimientos injustos, como consecuencia de la vulneración de sus derechos humanos, producida entre los años 1960 y 1978 en el contexto de la violencia de motivación política vivida en la Comunidad Autónoma del País Vasco. (Normativa autonómica).El Decreto 1/2011, de 11 de enero, de modificación del Decreto 31/2009, de 10 de febrero, de creación y regulación del Consejo Consultivo de Educación en Derechos Humanos y por la Paz. (Normativa autonómica).

»El Decreto 55/2010, de 23 de febrero de regulación del Consejo de Participación de Víctimas del Terrorismo. (Normativa autonómica).

En esta normativa se asienta el Plan de Paz y Convivencia 2013-2016 de la Secretaria General para la Paz y la Convivencia del Gobierno Vasco, aprobado el 26 de noviembre de 2013 (Secretaria General para la Paz y la Convivencia del Gobierno Vasco, 2014). A nivel institucional, en la Comunidad Autónoma del País Vasco, las iniciativas más destacables en materia de paz y convivencia donde la cuestión de la memoria tiene un espacio notable, son el citado Plan de Paz y Convivencia 2013-2016 del Gobierno Vasco, y el Plan de Derechos Humanos, Recuperación de la memoria y Convivencia 2012-2015, de la Diputación Foral de Gipuzkoa.

El plan de la administración provincial de Gipuzkoa tiene como objetivo recuperar la memoria histórica de las diferentes violencias del conflicto en base al derecho a la verdad, la justicia y la reparación. En el plan se explicita la necesaria implicación de agentes sociales, partidos políticos, sindicatos, etc., para llevar a cabo tareas de recuperación de la memoria, esclarecimiento de hechos, asesoría, documentación y elaboración de recomendaciones. Además de incidir en la necesidad de esclarecer las vulneraciones de derechos humanos ocurridas en el marco del conflicto del País Vasco, apunta a la necesidad de acercarnos a los motivos subyacentes a dichas vulneraciones. Esto enfatiza el trabajo sobre dos aspectos de la memoria, la necesidad de esclarecer los hechos objetivos y la importancia de conocer los factores que los determinaron.

Por su parte, la iniciativa del Gobierno Vasco incide en el deber de clarificar lo sucedido en el marco del conflicto desde un tratamiento integral de las vulneraciones a los derechos humanos, con una valoración específica para cada uno de los orígenes, especialmente el vinculado a ETA. En este sentido, el plan parte de un principio de verdad, entendido como "Evitar una verdad a medias, reprimida o amnésica: configurar, a través del relato objetivo de los hechos, la verdad compartida sobre las violaciones contra los derechos humanos" (Secretaria de Paz y Convivencia del Gobierno Vasco, 2014: 9), y de un principio de responsabilidad, referido a "Determinar y reconocer la responsabilidad de cada cual en el pasado y las consecuencias relativas a las vulneraciones de los derechos humanos" (Secretaria de Paz y Convivencia del Gobierno Vasco, 2014: 10).

Entre los objetivos del plan, hay tres que hacen referencia a cuestiones vinculadas a la memoria, como son: realizar una constatación de todas las vulneraciones de derechos humanos, completar el proceso de reconocimiento y reparación a todas las víctimas, y 
definir e impulsar una política pública de memoria. Las iniciativas específicas del plan asociadas a estos objetivos son: 1) Realización de informes sobre vulneraciones de Derechos Humanos y acciones derivadas, 2) Desarrollo del proyecto Instituto de Memoria y Convivencia, 3) Contribución al Memorial de Víctimas del Terrorismo, 4) Apoyo, reconocimiento y reparación a las víctimas del terrorismo, 5) Apoyo, reconocimiento y reparación a las víctimas sin amparo en la actual legislación, y 6) Investigación y acción sobre la tortura. Estas iniciativas del plan están previstas para ser implementadas y desarrolladas desde el año 2014.

Un aspecto común a ambas iniciativas es la necesidad de que el trabajo por la memoria de las víctimas se realice desde una perspectiva incluyente, es decir, donde tengan cabida todas las víctimas de vulneraciones de derechos humanos y de crímenes de motivación política. En este sentido, la Asociación Pro-Derechos Humanos Argituz (2012) propone una serie de cuestiones para desarrollar una memoria incluyente en el País Vasco, como son:

» Recoger las diferentes vulneraciones de derechos humanos, además de una crítica moral hacia las mismas.

» Mostrar respeto por el dolor y la dignidad de todas las víctimas, sobre todo aquellas consideradas como de otro color político.

»Afrontar las ambivalencias, cuestionamientos o afectos negativos de una memoria incluyente sin utilizarlos contra los colectivos ajenos al propio.

» Focalizar su aportación a la restauración de la convivencia.

» Asentar una base común de respeto a los derechos humanos más allá de las diferencias políticas.

En este trabajo coordinado por Martín Beristain sobre los desafíos que conlleva el desarrollo de una memoria incluyente en el ámbito local del País Vasco (Argituz, 2012), nos encontramos con cuestiones que van más allá de lo estrictamente local. De manera general, se enfatiza la necesidad de establecer una definición común de víctima donde tengan cabida todas las personas que han sufrido vulneraciones de derechos humanos, partiendo de la que establece la normativa internacional. La definición de víctima ha sido parte de la lucha política vinculada al conflicto y la paz en el País Vasco; esto se ha visto reflejado en los discursos defensivos donde se muestra, por un lado, una falta de reconocimiento a víctimas cuyo victimario es de la propia familia política, y por otro, la creencia de ser las únicas víctimas del conflicto, procesos psicosociales implicados en conflictos profundos (Bar-Tal, 2007).

Según los artículos 8 y 9 de la Resolución 60/147 de 2005, de la Asamblea General de las Naciones Unidas.

"Se entenderá por víctima a toda persona que haya sufrido daños, individual o colectivamente, incluidas lesiones físicas o mentales, sufrimiento emocional, pérdidas económicas o menoscabo sustancial de sus derechos fundamentales, como 
consecuencia de acciones u omisiones que constituyan una violación manifiesta de las normas internacionales de derechos humanos o una violación grave del derecho internacional humanitario. Cuando corresponda, y en conformidad con el derecho interno, el término "víctima" también comprenderá a la familia inmediata o las personas a cargo de la víctima directa y a las personas que hayan sufrido daños al intervenir para prestar asistencia a víctimas en peligro o para impedir la victimización. Una persona será considerada víctima con independencia de si el autor de la violación ha sido identificado, aprehendido, juzgado o condenado y de la relación familiar que pueda existir entre el autor y la víctima."

Como eje fundamental de una política de memoria incluyente, en el informe de Argituz se enfatiza la necesidad de esclarecer la verdad de vulneraciones de derechos humanos que no han sido esclarecidas desde ninguna instancia. Además, se pone el acento en que los diversos actores deben reconocer su vinculación a las conculcaciones de derechos humanos para esclarecer la verdad de los hechos.

Estas cuestiones son de gran importancia para profundizar en la reparación moral de las víctimas que han sido de alguna manera deslegitimadas, o que han visto como las medidas de reparación establecidas no han logrado su dignificación. En todo caso, se indica que es muy importante dar legitimidad a los testimonios de las víctimas, tanto a aquellas con las que se comparte ideario político como a las que no. Esta cuestión se considera central de cara a facilitar una expresión global de rechazo a las vulneraciones de derechos humanos, y un reconocimiento plural de las víctimas.

Para poder avanzar en la construcción de una memoria incluyente relativa a las vulneraciones de derechos humanos, constatan la importancia de elementos de carácter psicosocial como, construir relaciones de confianza entre víctimas de diferente origen, evitar la politización de los actos de reconocimiento y reparación simbólica, y hacer que las víctimas sean partícipes en la construcción del sentido de dichos actos. También afirman que la construcción de una memoria incluyente requiere de elevadas dosis de reconocimiento mutuo y de empatía con el diferente, con tal de romper con los estereotipos negativos sobre el otro y posibilitar su rehumanización.

\section{Procedimiento del estudio}

El objetivo principal del estudio era recabar ideas para avanzar en la construcción de memorias incluyentes como parte del proceso de paz que se está viviendo actualmente en el País Vasco. Como se ha explicitado en la parte introductoria del artículo, se considera que el trabajo por la memoria en el País Vasco presenta dos grandes dimensiones que, aún estando vinculadas entre sí, hacen referencia a aspectos de distinta índole: la construcción de la verdad sobre las vulneraciones de derechos humanos, como dere- 
cho reconocido de las víctimas y sus supervivientes por el derecho internacional, y la construcción de visiones subjetivas del pasado menos defensivas y reactivas donde se puedan integrar distintos puntos de vista.

El derecho a la verdad implica el esclarecimiento de los hechos donde se produjo la vulneración, identificar a los responsables de la misma, y a poder ser, conocer los motivos que llevaron a dichos responsables a realizar los crímenes cometidos. En relación a las construcciones sociales y subjetivas de la historia del conflicto, el trabajo por la memoria se plantea con vistas a posibilitar el desarrollo de memorias colectivas incluyentes, complejas y flexibles, que tengan en cuenta diferentes criterios de interpretación y análisis, y que impliquen la adopción de puntos de vista diferentes.

Para realizar el estudio se implementaron 25 entrevistas semiestructuradas a 11 mujeres y 14 hombres, con edades comprendidas entre los 32 y los 78 años y con una media de 53 años. 7 participantes estaban vinculados a diversos partidos políticos vascos -PP, PSE, PNV, EA, Aralar, Alternatiba, Sortu-, y 18 agentes sociales vascos, como movimientos y organizaciones sociales que trabajan por la paz y los derechos humanos, la iglesia, y la universidad. La muestra abarca todo el espectro sociopolítico vasco caracterizado por las cuatro familias sociopolíticas vascas tradicionales -centralismo conservador, republicanismo progresista, nacionalismo moderado e izquierda abertzale - teniendo en cuenta que no son categorías estancas sino borrosas, debido a la heterogeneidad existente dentro de ellas. También participaron en el estudio personas que no se identifican con ninguna de estas cuatro familias sociopolíticas.

La selección de las personas entrevistadas se llevó a cabo de manera incidental, a través de contactos personales del investigador con diversos agentes sociales y políticos vascos, fruto de otros proyectos de intervención e investigación para la paz en el País Vasco. El criterio por el que estas personas fueron seleccionadas para participar en el estudio fue su implicación activa con la paz en el País Vasco, plasmada en su participación en espacios de construcción de paz. La participación se realizó a título individual, no en calidad de representante de la organización de referencia de cada participante, y bajo anonimato y confidencialidad.

Las entrevistas, gravadas y transcritas en su totalidad, se centraron en conocer las visiones de los/as participantes sobre cómo realizar el trabajo por la memoria en la coyuntura actual, tanto en relación a las víctimas y las vulneraciones de derechos humanos, como en relación a las interpretaciones subjetivas del pasado. Así, la implementación de la entrevista se desarrolló en tres partes: una primera donde se expusieron los objetivos del estudio, una segunda basada en cómo avanzar en la construcción de memorias colectivas más abiertas, y una tercera centrada en cómo llevar a cabo la tarea de construir la verdad para reparar a las víctimas de vulneraciones de derechos humanos cometidas en el contexto del conflicto y la violencia en el País Vasco.

Además de las entrevistas, se creó un espacio de diálogo de 5 horas centrado en cómo hacer el trabajo por la memoria, donde participaron 14 personas -8 mujeres y 7 
hombres-, con edades comprendidas entre 32 y 63 años, con una media de edad de 47, y pertenecientes a distintos agentes sociales y políticos del País Vasco. La selección de la muestra se realizó entre personas que habían sido entrevistadas, y otras personas que fueron seleccionadas por su implicación en la paz en el País Vasco, con tal de completar un grupo plural.

El espacio de diálogo se desarrolló aplicando la herramienta de diálogo Open Space Technology (Owen, 1997), un Método de Diálogo con Grandes Grupos (Holman, Devane y Cady, 2007), que está basado en la autoorganización grupal y la creatividad colectiva para tratar temas complejos. En el inicio de la jornada el colectivo de participantes decidió tratar 4 cuestiones vinculadas a la memoria, como son la construcción de un relato mínimo común, la participación ciudadana en la construcción del relato, las políticas públicas de memoria, y el esclarecimiento de la verdad de las vulneraciones de derechos humanos. Durante la jornada, se crearon tres grupos de diálogo en dos franjas horarias para tratar los temas, con una puesta en común de lo tratado en cada espacio y una reflexión personal libre al cerrar la sesión. En cada uno de los espacios de diálogo se redactó un acta con las cuestiones abordadas.

Las entrevistas realizadas fueron analizadas mediante la técnica de análisis del discurso, mientras que las actas de las conversiones mantenidas durante el espacio de diálogo fueron analizadas mediante un análisis de contenido por categorización.

\section{Resultados del estudio}

Desde la perspectiva de los testimonios recogidos, las dos dimensiones planteadas respecto al trabajo por la memoria - esclarecimiento de la verdad sobre las vulneraciones a los derechos humanos cometidas en el marco del conflicto vasco, y la construcción de visiones sobre el pasado más amplias y complejas- implican objetivos diversos dentro de la meta general de construir un escenario de paz sostenible. De manera concreta, las personas participantes plantean objetivos vinculados a a) reconocer, dignificar y reparar a las víctimas, b) apoyar la creación de un marco de convivencia basado en el respeto a los derechos humanos, c) generar garantías de no repetición de los hechos, d) construir discursos deslegitimadores de las distintas formas de violencia, e) reconstruir el tejido social desde el cambio en elementos psicosociales característicos de las sociedades en conflicto, como actitudes confrontacionales, percepciones prejuiciosas, etc. Vemos como los objetivos planteados van más allá de la memoria propiamente dicha, incluyendo transformaciones estructurales, sociales y psicosociales para construir un presente y futuro de convivencia. El trabajo por la memoria es visto como un posible catalizador de cambios psicosociales importantes para la construcción de la paz en el País Vasco. 
Por otro lado, tanto las personas entrevistadas como el grupo de diálogo aportaron ideas diversas sobre las implicaciones que tiene el trabajo por la memoria, y sobre cómo plasmar esas implicaciones en la realidad del proceso de paz. Un elemento destacado por muchos participantes es la necesidad de tiempo para llevar a cabo un trabajo exhaustivo sobre la memoria, que conlleve tanto el esclarecimiento de las vulneraciones de derechos humanos como la construcción de interpretaciones del pasado más ricas e incluyentes. El factor tiempo pone de relevancia el carácter procesual y dinámico con el que debe apreciarse el trabajo por la memoria. En los discursos de las/os participantes se han encontrado diferentes percepciones sobre la temporalidad del proceso, aunque de manera general se coincide, por un lado, en la necesidad de generaciones para poder tejer un sistema de creencias sobre el pasado con uno mínimo común más amplio, y por otro, en la necesidad de celeridad en el proceso de esclarecer la globalidad de las vulneraciones de derechos humanos.

Sobre el esclarecimiento de las vulneraciones, los resultados señalan que existe la necesidad de esclarecer todas las vulneraciones a los derechos humanos cometidas en el marco del conflicto vasco. Encontramos divergencias en cuanto a la fecha de partida desde donde esclarecer las vulneraciones, ya que hay personas que entienden que deberían hacerse visibles todas las vulneraciones de la guerra civil y de la dictadura, y otras que lo vinculan al periodo de actividad armada de ETA, afirmando que se trata de dos procesos históricos diferenciados. Esta divergencia ejemplifica las diferentes interpretaciones del pasado del conflicto vasco, y cómo éstas influyen en la percepción sobre la dimensión temporal que debe tomarse en consideración para esclarecer la verdad como derecho de las víctimas.

Como fórmula de trabajo para esclarecer las vulneraciones de derechos humanos, los discursos han planteado diferentes posibilidades, como crear grupos de investigación interdisciplinares y plurales desde un punto de vista sociopolítico que, de manera autónoma e independiente, clarifiquen todas las vulneraciones cometidas durante el periodo de tiempo que se consensúe al efecto. En este sentido, los resultados indican la posibilidad de imbricar los ámbitos académico, político y social en la tarea de satisfacer el derecho a la verdad de las víctimas, generando espacios de trabajo conjunto entre miembros de organizaciones sociales que trabajan temas de paz y derechos humanos, académicos expertos en la materia, y miembros de las instituciones.

Los resultados señalan a la oportunidad de utilizar diferentes procedimientos para recopilar datos, con tal de esclarecer las vulneraciones a los derechos humanos. Por un lado, se ha puesto el énfasis en lo objetivo, es decir, en recopilar y documentar las vulneraciones mediante datos de archivo, documentación e informes oficiales, y estudios e investigaciones realizados al efecto, que nos aporten datos "duros", objetivables, sobre las vulneraciones cometidas por ETA y grupos afines, y por el Estado y grupos para-policiales. Una segunda vía hace referencia a la subjetividad, a las vivencias de las personas que han visto vulnerados sus derechos. En este caso se plantea la posibilidad 
de abrir espacios de recopilación de testimonios donde víctimas de diferentes perpetradores y personas cercanas a las mismas aporten las vivencias de las vulneraciones padecidas. Una cuestión importante planteada respecto a la toma de testimonios es seguir criterios de voluntariedad, inclusividad y legitimación, para que todas las personas que quieran aportar su testimonio puedan hacerlo sabiendo que se va a otorgar credibilidad y legitimidad al mismo.

Entre los obstáculos planteados por las/os participantes, se indica la posibilidad de que víctimas de diferentes perpetradores tengan reticencias a participar en un proceso de aportación de testimonios junto con víctimas de distinto origen, es decir, víctimas de ETA, del Estado o de grupos para-policiales que no quieran participar conjuntamente en un proceso de aportación de testimonios. Ante esta cuestión, se plantea la posibilidad de crear espacios diferentes para víctimas de ETA y grupos afines, y para víctimas de agentes del Estado y grupos para-policiales, que resulten en informes paralelos sobre vulneraciones para satisfacer el derecho a la verdad, espacios que puedan funcionar en paralelo con otros donde víctimas de diferente origen quieran aportar sus testimonios en un proceso conjunto.

Un obstáculo vinculado a esta cuestión es la reticencia de algunas víctimas a aparecer en una fotografía completa de vulneraciones cometidas en el marco del conflicto vasco. Este hecho puede ser interpretado como una comparación o jerarquización entre víctimas, o simplemente que víctimas de un victimario no quieran aparecer con víctimas de otro en un mismo esquema explicativo de las vulneraciones que se han cometido. Ante esta cuestión se incide en la necesidad de buscar alguna fórmula consensuada para que, por un lado, se garantice la igualdad sobre el derecho de las víctimas a la verdad, y por otro, la sociedad pueda conocer la globalidad de las vulneraciones perpetradas y con ellas construir memorias más ricas y complejas sobre el pasado.

Este derecho a la verdad incluye otra cuestión controvertida, como es el esclarecimiento de las responsabilidades concretas de los diferentes agentes sobre las vulneraciones, y unida a ella, los motivos que les llevaron a realizar dichas vulneraciones. En los discursos aportados se perciben posturas diversas al respecto. Hay personas que plantean como necesario esclarecer los hechos además de las motivaciones, y otras que sólo ven necesario lo primero. Se indica que el no reconocimiento de las responsabilidades en el daño perpetrado obstaculiza el derecho a la verdad de las víctimas. Ante esta cuestión, se hace explícitamente necesaria la implicación de ETA y grupos afines, así como del Estado, para esclarecer los motivos de las vulneraciones cometidas.

Por otro lado, se señala que muchas víctimas necesitan una explicación de los motivos existentes detrás de los hechos para dotar de significado a sus propias vivencias. Además, se ha señalado que las posibles peticiones de perdón y de disposición a reparar por parte de los distintos victimarios pasan necesariamente por un reconocimiento expreso del daño causado. Siguiendo con la participación de los perpetradores en la construcción de la verdad, los resultados indican que su testimonio sincero tiene una rele- 
vancia central para esclarecer los hechos y motivaciones. Además, algunos testimonios añaden que sería positivo para la reparación moral de las víctimas un reconocimiento negativo de los hechos cometidos.

Un último aspecto mencionado sobre el esclarecimiento de la verdad se refiere a la politización de todo lo que gira alrededor de las víctimas. Se han encontrado discursos en personas con vivencias y posiciones divergentes sobre el conflicto, que afirman necesario abandonar la utilización política de las víctimas con fines partidistas y electoralistas en relación a la cuestión del derecho a la verdad. Se ha expresado que desde diferentes sectores se manipula mediáticamente y se utiliza el sufrimiento, vehiculizando el dolor de las víctimas para obtener réditos. Por ello, se apunta al abandono de estas posiciones como una cuestión necesaria para generar un proceso incluyente que permita esclarecer todas las vulneraciones a los derechos humanos cometidas en el marco del conflicto vasco.

En relación al segundo aspecto del trabajo por la memoria, es decir, el vinculado a la construcción de visiones del pasado más amplias e incluyentes, y menos defensivas y reactivas, los resultados inciden en tres cuestiones fundamentales. En primer lugar, señalan la imposibilidad de desarrollar una visión compartida del pasado para toda la sociedad vasca, es decir, una memoria colectiva común, dada la pluralidad de la sociedad vasca en términos sociopolíticos e identitarios, lo cual está unido a diferentes vivencias sobre el conflicto. Además, distintos discursos han apuntado que una visión única del pasado sería negativa, incluso se plantea como un reflejo antidemocrático y asociado a formas de pensamiento único. A pesar de ello, se incide en que es necesario acercarse a un mínimo común compartido por toda la sociedad, y que ese mínimo común debe pivotar sobre el reconocimiento de todas las vulneraciones a los derechos humanos. Los resultados señalan la necesidad de generar espacios y procesos comunicativos donde personas con diferentes vivencias y visiones del pasado puedan compartirlas para ampliarlas, hacerlas más complejas, e incluso incluir la visión del otro como parte de la visión propia del pasado.

A este respecto, las personas participantes plantean una segunda cuestión fundamental para crear memorias más inclusivas, como es la participación ciudadana, señalando la necesidad de crear espacios seguros de diálogo donde personas vinculadas a agentes sociales y políticos, y miembros de la ciudadanía en general, puedan intercambiar puntos de vista sobre el pasado. En este sentido, se ha enfatizado el trabajo a nivel local. La creación de espacios seguros para el diálogo entre personas que viven y piensan el conflicto y la paz de manera diferente se plantea como una herramienta importante para la reconstrucción del tejido social. El intercambio de visiones entre personas con diferente vinculación política, incluyendo conocimientos sobre hechos desconocidos por otros, además de favorecer la amplitud de las visiones sobre el pasado, facilita la reconstrucción de prácticas sociales, y con ellas la posibilidad de generar memorias colectivas más incluyentes y menos reactivas. 
Por último, se incide en que la construcción de visiones más amplias y complejas del pasado puede verse favorecida por el primer aspecto del trabajo por la memoria, es decir, por la construcción de una verdad incluyente sobre las vulneraciones de derechos humanos. Legitimar institucional, política y socialmente una verdad completa de los hechos, haciendo que las diferentes familias políticas vascas reconozcan la globalidad de las vulneraciones a los derechos humanos ha sido planteado como un elemento que puede favorecer el desarrollo de memorias colectivas con un mayor mínimo común compartido. Los resultados inciden en que, además de los hechos, el esclarecimiento de los motivos por los que éstos se cometieron, puede contribuir a generar visiones más amplias y complejas del pasado, resaltándose que conocer el máximo de detalles sobre la realidad es la mejor forma de poder tener visiones amplias de la misma.

\section{Reflexiones finales Implicaciones de una memoria inclusiva para el País Vasco}

Las visiones del pasado se construyen socialmente en el presente con miras a construir un futuro deseado. Las élites partidistas y las posiciones más rígidas de los grupos sociopolíticos presentes en el País Vasco muestran intereses en propiciar memorias colectivas que expliquen el pasado según visiones exclusivas y defensivas, haciendo hincapié en las atrocidades cometidas por el enemigo o rival político, en el papel de víctima del propio grupo, y en el rol de salvador de los valores morales más elevados como la libertad, la democracia o el patriotismo. A pesar de esta lucha por la memoria en el discurso público, nos encontramos cada vez con más voces que plantean como necesaria la inclusividad en la memoria para avanzar hacia la paz en el País Vasco, voces como las que han participado en este estudio, todas ellas con un papel activo en la construcción de paz en sus distintos ámbitos. No podemos concluir que los resultados expuestos en el presente artículo son extrapolables a la ciudadanía vasca en su conjunto, solamente a las personas participantes en el mismo. A partir de los datos obtenidos no se puede concluir que la sociedad vasca plantee el trabajo por la memoria en estos términos, pero sí consideramos que dentro de los espacios de trabajo para la paz se está avanzando en este sentido. A modo de ejemplo, tal y como apunta el Euskobarómetro de noviembre de 2014 en relación a las víctimas de ETA (Euskobarómetro, 2014), el $47 \%$ de los ciudadanos vascos prefiere pasar página ante el sufrimiento de las víctimas, mientras que el $44 \%$ considera que sería conveniente abordarlo. A pesar de ello, en un estudio anterior se encontró que el trabajo por la memoria es un elemento central para la construcción de la paz en el País Vasco (Mínguez-Alcaide, Alzate y Sánchez, 2014).

En el presente artículo se han apuntado una serie de claves sobre la memoria y su papel en los conflictos profundos y en situaciones de construcción de paz, con la 
finalidad última de realizar una pequeña contribución a la construcción de la paz en el País Vasco en lo referente al pasado. En este trabajo se ha tratado de aportar una visión amplia de la memoria, desde dos dimensiones de ésta estrechamente ligadas al conflicto y la paz, como son las representaciones compartidas del pasado por los grupos de identidad, y el derecho a la verdad de las víctimas de vulneraciones de derechos humanos como parte de su reparación integral.

Tras los resultados obtenidos mediante las entrevistas y el grupo de diálogo, y teniendo en cuenta los marcos teóricos de referencia sobre las dos dimensiones de la memoria abordadas en este estudio, se considera preciso plantear algunas reflexiones finales a modo de recomendaciones sobre el trabajo por la memoria.

Un aspecto destacado por las/os participantes que responde al derecho a la verdad de todas las víctimas, tal y como aparece en la legislación internacional y en las iniciativas institucionales por la paz en el País Vasco, es la necesidad de esclarecer el mapa completo de vulneraciones a los derechos humanos cometidas en el marco del conflicto vasco. Construir una memoria inclusiva donde tengan cabida todas las vulneraciones de derechos humanos implica aceptar una victimización plural, con distintos orígenes, formas y grados, y por lo tanto, aceptar la existencia de diferentes perpetradores. Este hecho tiene distintas implicaciones. En positivo, esclarecer todas las vulneraciones cometidas por ETA, agentes del Estado y grupos parapoliciales y de extrema derecha, acompañadas por un reconocimiento del daño causado a las víctimas, supone responder a su derecho a la verdad y a la reparación. Para la sociedad en su conjunto puede ser un ejercicio que contribuya a generar conciencia colectiva sobre el sufrimiento, ayudar a deslegitimar las distintas formas de violencia manifestadas en el conflicto vasco y, con ello posibilitar la garantía de su no repetición.

En términos negativos, aceptar una visión amplia de la victimización y el sufrimiento, para algunos colectivos supone revisar la atribución única de víctima a las del propio grupo sociopolítico, y superar la negación del sufrimiento y la victimización del supuesto enemigo político. Aceptar esta fotografía completa implica aceptar la dignidad y la humanidad del otro, re-incluir moralmente y re-humanizar a los miembros de los grupos enemigos a los que se excluye de cualquier criterio moral aplicable a cualquier ser humano, como le ha sucedido con víctimas de ETA, del GAL y de grupos de extrema derecha, o víctimas de torturas cometidas por agentes de las Fuerzas y Cuerpos de Seguridad del Estado. Si la memoria cumple la función de salvaguardar la identidad colectiva, exponer memorias defensivas a relatos que contradicen la propia visión puede ser una fuente de riesgo para la identidad. Reconocer vulneraciones cometidas y otorgarles un rango negativo en términos éticos, supone un riesgo para la autoestima grupal, ya que implica abandonar el desenganche moral con el que se interpretan las vulneraciones cometidas por el propio grupo sociopolítico y/o identitario. Unido a estos procesos psicosociales de naturaleza moral, se plantea revertir la imagen que se tiene del supuesto enemigo, una imagen caracterizada por su demonización, por 
una imagen de rival político legitimado democráticamente, y se considera prioritario superar el odio, el miedo y el rencor por una empatía realista basada en comprender las vivencias y visiones del otro (White, 1984). Por tanto, se aboga por avanzar en la concreción del derecho a la verdad de todas las víctimas, y por el cambio en procesos psicosociales de tipo actitudinal, perceptivo, emocional y moral que obstaculizan la reparación del sufrimiento en toda su amplitud.

En relación a los significados sobre el pasado, construir una memoria única se vislumbra como imposible, además de negativo por la posibilidad de caer en el dogma y en la uniformidad social de pensamiento. A pesar de ello, se considera que es posible construir socialmente un mínimo común compartido basado en el reconocimiento de las vulneraciones de derechos humanos, de los hechos y las motivaciones subyacentes a los mismos. A partir de ahí, es preciso asumir y aceptar la existencia de diferentes relatos, ya que éstos vienen condicionados por vivencias personales y factores vinculados a la pertenencia ideológica e identitaria, pero también la posibilidad de abrir las visiones defensivas y reactivas del pasado. La construcción de relatos más incluyentes implica transformar visiones rígidas sobre el pasado, en muchos casos polarizadas, por visiones más amplias y complejas de lo sucedido en el País Vasco durante las últimas décadas. Una cuestión importante al respecto, y que tiene implicaciones en la reconstrucción del tejido social, es la inclusión del relato del otro en la propia visión, es decir, desde esa empatía realista que permite ver la realidad desde el punto de vista del otro.

Finalmente, en cuanto al cómo abordar la memoria, se coincide con las tareas que la ONU otorga a las comisiones de la verdad, que han aparecido en los discursos de los/ as participantes, y que son parte de las iniciativas institucionales para la paz en el País Vasco. En primer lugar, destacar como primordial el generar espacios de trabajo donde las instituciones y partidos políticos, el mundo académico y la sociedad civil esclarezcan lo sucedido en cuanto a vulneraciones a los derechos humanos, en marcos de trabajo independientes de injerencias políticas. Para ello, es fundamental que los partidos políticos renuncien a sus posiciones e intereses partidistas sobre el relato y ayuden a promover la legitimidad social sobre el testimonio de todas las víctimas.

Los discursos han apuntado a la necesidad de dialogar sobre el pasado como herramienta para favorecer la reconstrucción del tejido social. Así, se explicita la necesidad de generar espacios de diálogo ciudadano donde poder intercambiar opiniones y visiones para tener una mayor comprensión de lo sucedido. El diálogo seguro favorece el desarrollo de cambios en los elementos psicosociales vinculados al conflicto, ya que permite poder expresar y escuchar, compartir y contrastar las visiones, además de transformar las prácticas sociales y relacionales. Por ello, y dada la importancia de lo local para la reconstrucción del tejido social, se plantea la posibilidad de crear espacios seguros de diálogo a nivel local para hablar sobre el pasado. De manera discreta, organizaciones sociales pertenecientes al movimiento vasco por la paz, como son Bakeola, Lokarri o Baketik, ya han iniciado tareas en este sentido. 


\section{Bibliografía}

Anderson, B. (1997): "The Nation and the Origins of National Consciousness", en M. Gibernau \& J. Rex, eds., The Ethnicity Reader: Nationalism, Multiculturalism and Migration. Cambridge, Polity Press.

Argituz (2011): Mapa (incompleto) de conculcaciones del derecho a la vida y a la integridad física y psíquica en relación a la violencia de motivación política. Extraído el 20.11.2012 de:

$<$ http://www.argituz.org/documentos/inf/mapacastfinal.pdf $>$

Argituz (2012): El Tiempo es Ahora. ¿Es posible una memoria incluyente de las víctimas en el ámbito local? Experiencias y desafios. Extraído el 14.02.2013 de:

$<$ http://www.argituz.org/documentos/inf/tiempoesahoracast.pdf $>$

Balibar, E. (1996): "Fictive Ethnicity and Ideal Nation", en J. Hutchinson \& A.D. Smith, eds., Ethnicity. Oxford, Oxford University Press.

BandurA, A. (1999): "Moral Disengagement in the Perpetration of Inhumanities", Personality and Social Psychology Review, 3 (3), pp.193-209.

BAR-TAL, D. (2007): "Sociopsychological Foundations of Intractable Conflict", American Behavioral Scientist, 50 (11), pp. 1430-1453.

Bourdieu, P. (1999): La miseria del mundo. Madrid, Akal

Coleman, P.T. (2004): Polarized Collective Identities: A Review and Synthesis of the Literature. New York, Columbia University.

Desroche, H. (1976): Sociología de la esperanza. Barcelona, Herder.

EusKobARÓMETRo (2014): Estudio periódico de la opinión pública vasca. Noviembre 2014.

Extraído el 19.12.2014 de

$<$ http://www.ehu.eus/documents/1457190/1525260/Euskobarometro+Noviembre+2014>

Gurr, T.R. (2000): Peoples Versus States: Minorities at Risk in the New Century. Washington, D.C., United States Institute of Peace.

Halbwacks, M. (1950): La memoria colectiva. Zaragoza, Prensas Universitarias de Zaragoza.

Haslam, N. (2006): "Dehumanization: An Integrative Review”, Personality and Social Psychology Review, 10 (3), pp. 252-264.

Holman, P., T. Devane \& S. Cady (2007): The Change Handbook. San Francisco, Barrett Koehler Publishers

Kelman, H.C. (1997): "Social-Psychological Dimensions of International Conflict", en William I. Zartman, ed., Peacemaking in International Conflict. Methods \& Techniques. Washington, United States Institute or Peace Press. 
Korostelina, K. (2007): "The system of social identities in Tajikistan: Early Warning and conflict prevention", Communist and Post-communist Studies XX, pp. 1-16.

Larizgoitia, I., I. Izarzugaza e I. Markez (2009): La noche de las víctimas. Investigación sobre el Impacto en la Salud de la Violencia Colectiva (ISAVIC) en el País Vasco. Vitoria-Gasteiz, Fundación Fernando Buesa Blanco Fundazioa.

Manero, R. y M.A. Soto (2005): “Memoria colectiva y procesos sociales”, Enseñanza e Investigación en Psicología, 10 (1), pp. 171-189.

Martín Beristain, C. y D. PÁEz (2000): Violencia, apoyo a las víctimas y reconstrucción del tejido social. Experiencias internacionales y el desafio vasco. Madrid: Editorial Fundamentos.

Mínguez-Alcaide, X. (2013): Una aproximación psicosocial al conflicto vasco. Construyendo la paz en Espacio Abierto. Tesis doctoral.

Mínguez-Alcaide, X., R. Alzate y M. Sánchez (2014): "La Paz en el País Vasco. Una interpretación desde los significados sociales", Revista de Paz y Conflictos, 7, pp. 53-77.

Opoтоw, S. (1990): “Deterring moral exclusion”, Journal of Social Issues, 46, pp. 173-182.

Owen, H. (1997): Open Space Technology: A User's Guide, San Francisco, Berrett-Koehler.

PÁEz, D. (1998): Memorias colectivas de procesos culturales y políticos. Bilbao, Universidad del País Vasco.

Ross, M.H. (1995): La cultura del conflicto. Las diferencias interculturales en la práctica de la violencia. Barcelona, Paidós.

Ross, M.H. (2010): "A collective memory and how the presente shapes the past: a Philadelphia story abourt George Washington and slavery." Canadian Political Science Association Meeting, Concordia University, Montreal, Canada.

Secretaria de Paz y Convivencia del Gobierno Vasco (2014): Plan de Paz y Convivencia 2013-2016. Un objetivo de encuentro social. Disponible en:

$<$ https://www.irekia.euskadi.net/assets/attachments/3814/Propuesta_del_Plan_de_ Paz_y_Convivencia.pdf?138511963> (Consulta: 19 de marzo 2014).

Smith, A.D. (1993): “The Ethnic Sources of Nationalism”, en Michael E. Brown, ed., Ethnic Conflict and International Security. New Jersey, Princeton University Press.

TAJfel, H. (1984): Grupos humanos y categorías sociales. Barcelona, Helder.

Todorov, T. (2000): Los abusos de la memoria. Madrid, Paidós.

TURNER, J.C. (1987): Resdescubrir el grupo social. Madrid, Morata.

Whiтe, R.K. (1984): Fearful warriors: A psychogical profile of U.S.-Soviet relations. New York, Free Press. 